\title{
Catalytic Conversion of Methanol to Hydrocarbons over different wt\% Ni-HZSM-5
}

\author{
Thamer Adnan Abdullah ${ }^{1}$ \\ ${ }^{1}$ Applied Sciences Department/Applied Chemistry Branch, University of Technology, Baghdad, Iraq
}

\begin{abstract}
Due to crude oil is limited, new resources for fuel and petrochemicals are important to be developed. Biogas or NG (Natural Gas) can be easily converted into methanol which can be reacted over zeolite to produce olefins and gasoline. HZSM-5 zeolite catalyst has been used in this study and its modification by $(0.5 w t \%, 1 w t \%$, $2 w t \%$ and $4 w t \%)$ Ni to convert methanol to hydrocarbons (MTH). Catalysts have been studied at different temperatures and at different loadings of Ni for their performance in the MTH reaction. ZSM-5 catalysts after modification were characterized by SEM and BET. It was found that 2\%Ni-ZSM-5 catalyst gives better results at $753 K$.
\end{abstract}

Keywords : (MTH) Methanol to Hydrocarbons, (MTO) Methanol to Olefins, (MTG) Methanol To Gasoline, HZSM-5

\section{Introduction}

HZSM-5 Zeolites are usually used to convert methanol into olefins [4], gasoline [5] and aromatics [6]. Methanol Conversion to light olefins (MTO) and other hydrocarbons aromatics like (MTH) is very important new viable chemical technology. This reaction can be catalyzing be the effective of solid acids to produce hydrocarbons however, the selective production of light olefins, especially ethylene and propylene. Olefins can be converted to other products over ZSM-5 based process. Modified zeolite ZSM-5 catalyst has been characterized by several techniques like XRD, SEM, BET etc. [7, 8]. Combine inside zeolite pores is improved selectivity towards aromatics [1,2, and 12]. Different metals doped ZSM-5 catalyst have studied by several workers and it has been shown the effect of different metals on product selectivity and catalyst deactivation, they have studied different metals for increasing the selectivity of different products [11]. Reaction mechanism among zeolites with different pore architectures and acidic strengths/densities [3, 14 and15].

\section{Experimental Work}

\subsection{Catalyst Modification}

The HZSM-5 zeolite with a Si/Al ratio of 80 has been used for (MTH). Zeolite HZSM-5 was modified with Nickel Nitrate solution. Thereafter, ZSM-5 catalyst with solution were dried at $338 \mathrm{~K}$ for $5 \mathrm{hr}$. and then calcined at $823 \mathrm{~K}$ for $5 \mathrm{hr}$, in this part the impurities will get burned and the desired metal oxide doped over HZSM-5 catalyst. ZSM-5 with $x$ weight percent representing the Ni element HZ(Ni). The ZSM-5 with zero weight percent of Ni is shown as HZ (0). Prepared catalysts are characterized by SEM and BET.

\subsection{Experimental Setup}

Nitrogen flow rate is regulated and kept constant during the experiment. Flow rate of methanol is controlled by using precipitating pump. Experimental setup is shown in Fig.1. Mixture of nitrogen and methanol is passed through preheater so that methanol is converted into vapor and mixes uniformly with nitrogen as carrier gas. Feed is then is pumped to reactor at pre-set temperature. Liquid and gaseous products collected from the bottom of reactor are analyzed using Gas Chromatography. 


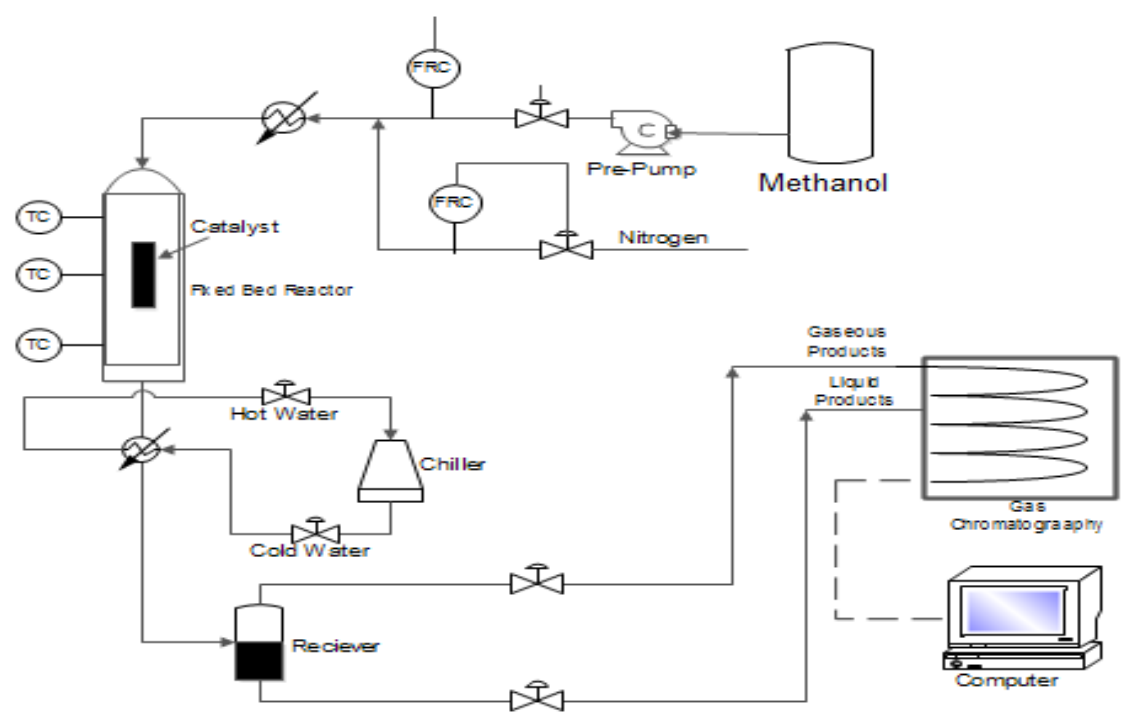

Fig. 1: Experimental Setup

\section{Result and Discussion}

\subsection{Physical Properties of the Catalysts}

With increase in weight \% of Ni over ZSM-5, BET surface area and pore volume are reduced as shown in Table 1. This is because of Ni doping sites in ZSM-5. Coking formation after $15 \mathrm{hr}$ run is reduced surface area but pore volume is not changed significantly. This means coking poison the catalyst is mainly on the surface of catalyst but not inside the pores.

TABLE I: Surface Area and Pore Volume

\begin{tabular}{|c|c|c|c|c|}
\hline \multirow[t]{2}{*}{ Catalyst } & \multicolumn{2}{|c|}{$\begin{array}{c}\text { SBET } \\
(\mathrm{m} 2 / \mathrm{gm})\end{array}$} & \multicolumn{2}{|c|}{$\begin{array}{l}\text { Pore Volume } \\
\text { Cm3 / gm }\end{array}$} \\
\hline & Fresh & Aged & Fresh & Aged \\
\hline $\mathrm{HZ}(4 \mathrm{Ni})$ & 211 & 196 & 0.275 & 0.274 \\
\hline $\mathrm{HZ}(2 \mathrm{Ni})$ & 213 & 201 & 0.274 & 0.273 \\
\hline $\mathrm{HZ}(1 \mathrm{Ni})$ & 216 & 200 & 0.275 & 0.274 \\
\hline $\mathrm{HZ}(0)$ & 225 & 207 & 0.278 & 0.277 \\
\hline
\end{tabular}

\subsection{SEM Analysis}

To investigate the morphology and picture of sample, SEM micrographs have been obtained. SEM images show that crystal grows into spherical polycrystalline aggregates and particle of undefined shape was also present as shown in Fig. 2. 


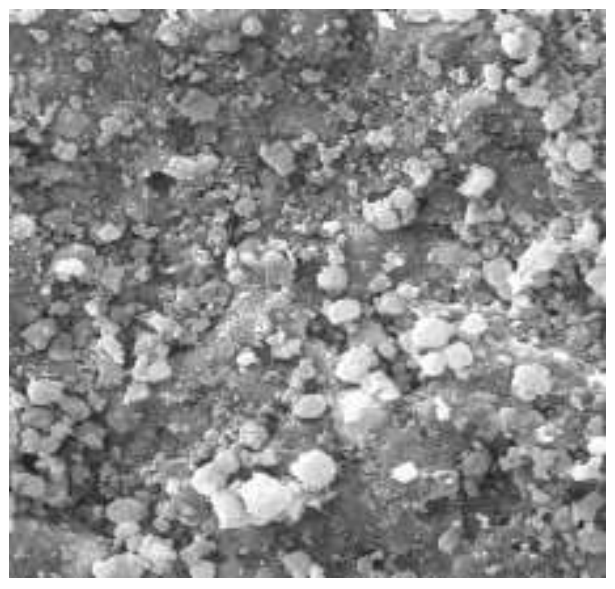

Fig. 2-a: SEM Image $2 \mathrm{wt} \% \mathrm{HZ}(\mathrm{Ni})$

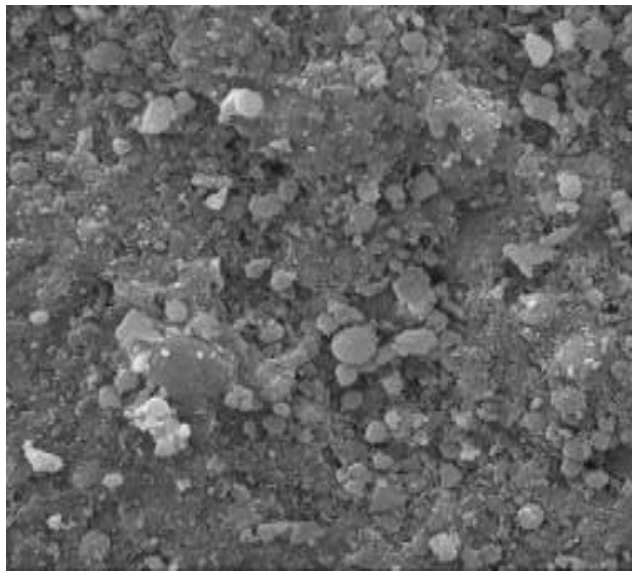

Fig. 2.b: SEM Image HZ(4 Ni)

\subsection{Effect of Runtime on the Conversion of Methanol}

Methanol conversion into hydrocarbons is dramatically improved when Ni content is $2 \%$. The catalyst can retain its activity after 15 hours without much loss in conversion. HZ(0), ZSM-5 without modification losses its activity much faster in the same time and conversion of methanol is reduced as shown in fig. 3 . In the case of $\mathrm{HZ}(0), \mathrm{HZ}(0.5), \mathrm{HZ}(1)$ and $\mathrm{HZ}(4)$ the activity of catalyst and conversion of methanol is less after $15 \mathrm{hr}$ run as compare with $\mathrm{HZ}(2)$.

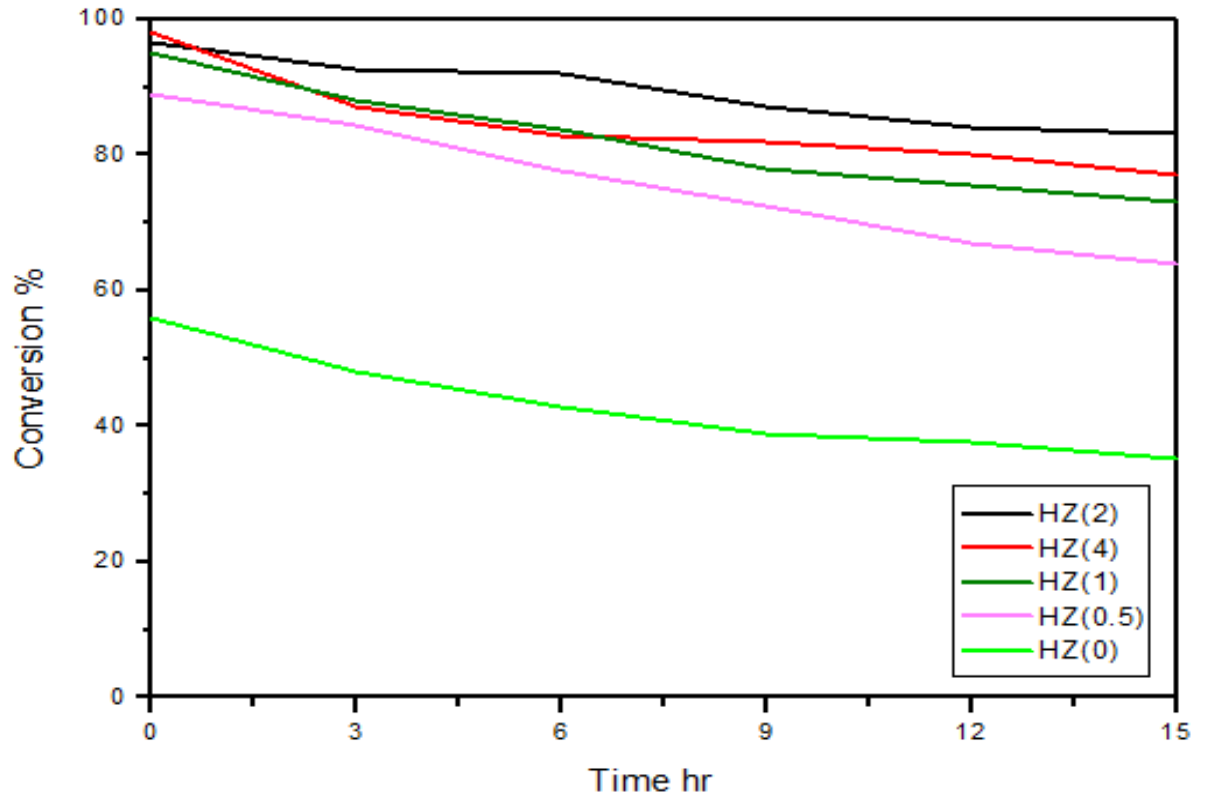

Fig. 3: Conversion of ethanol versus Time in a Fixed Bed Reactor $\left[\mathrm{T}=450{ }^{\circ} \mathrm{C}, \mathrm{P}=1 \mathrm{~atm}\right.$ and $\left.\mathrm{WHSV}=4.5 \mathrm{~h}^{-1}\right]$

\subsection{Effect of Runtime on the yield of Total hydrocarbons}

The reaction result is decreased with time, as shown in Fig.6. the decreases in the yield of hydrocarbons after 15 hours run experiment, hydrocarbon yield of $2 \mathrm{wt} \%$ Ni modified catalyst is nearly double as compared to unmodified catalyst. This means catalyst can be used for more time before regeneration and the operation would be lower cost. 


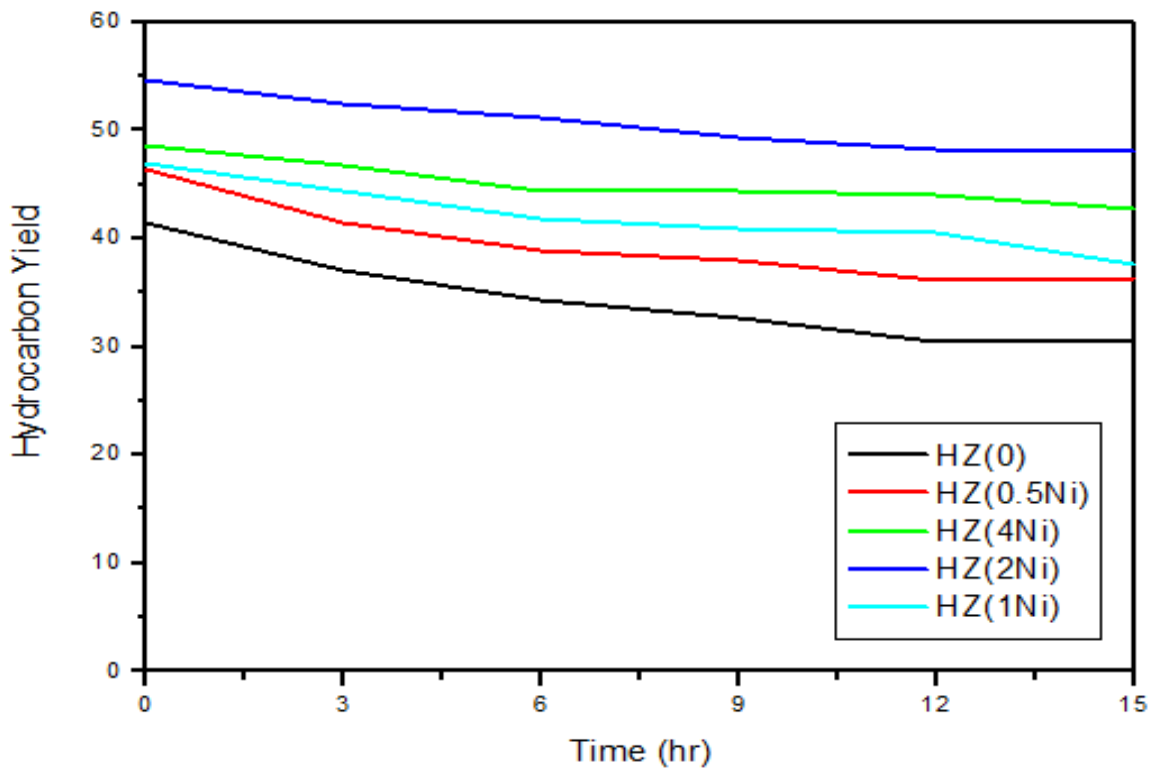

Fig. 6: Yield of Hydrocarbon versus Time in a Fixed Bed Reactor

$\left[\mathrm{T}=450^{\circ} \mathrm{C}, \mathrm{P}=1 \mathrm{~atm}\right.$ and $\left.\mathrm{WHSV}=4.5 \mathrm{~h}^{-1}\right]$

\section{Conclusions}

The performance of catalyst involved Ni-loaded ZSM-5 has been recognized in conversion of methanol to hydrocarbons. Conversion of methanol to hydrocarbons yield increased on $2 \mathrm{wt} \% \mathrm{HZ}(\mathrm{Ni})$. These experiments suggest that Ni species would interact with the acid sites of ZSM-5 to reduce the strength of strong acidic sites. The effect of temperate on the methanol conversion and hydrocarbons yield was observed. It was shown 2 wt $\%$ $\mathrm{HZ}(\mathrm{Ni})$ is the recommended catalyst and $723 \mathrm{~K}$ is the recommended temperature. Therefore $2 \mathrm{wt} \% \mathrm{Ni}$-doped ZSM-5 catalyst is high selectivity to gasoline-ranged hydrocarbons, and showed more resistance to deactivation.

\section{Acknowledgments}

The Author (Thamer Adnan Abdullah) would like to express their appreciation to the Ministry of Higher Education and Scientific Research in Iraq and University of Technology, Baghdad, Iraq for supporting this work.

\section{References}

[1] Jin, Y., Asaoka, S., Zhang, S., Li, P., and Zhao, S. (2013). Reexamination on transition-metal substituted MFI zeolites for catalytic conversion of methanol into light olefins. Fuel Processing Technology, 115, 34-41. http://dx.doi.org/10.1016/j.fuproc.2013.03.047

[2] Conte, M., Lopez-Sanchez, J. A., He, Q., Morgan, D. J., Ryabenkova, Y., Bartley, J. K., ... and Hutchings, G. J. (2012). Modified zeolite ZSM-5 for the methanol to aromatics reaction. Catalysis Science \& Technology, 2(1), 105112. http://dx.doi.org/10.1039/C1CY00299F

[3] Cui, Z. M., Liu, Q., Bain, S. W., Ma, Z., and Song, W. G. (2008). The role of methoxy groups in methanol to olefin conversion. The Journal of Physical Chemistry C, 112(7), 2685-2688. http://dx.doi.org/10.1021/jp710491h

[4] Corma, A. (1997). From microporous to mesoporous molecular sieve materials and their use in catalysis. Chemical reviews, 97(6), 2373-2420. http://dx.doi.org/10.1021/cr960406n

[5] Klyueva, N. V., Tien, N. D., and Ione, K. G. (1985). Hydrocarbon synthesis from methanol on erionite and mordenite catalysts synthesized in the presence of B3+, Ga3+ or Fe3+. Reaction Kinetics and Catalysis Letters, 29(2), 427-432. http://dx.doi.org/10.1007/BF02068537 
[6] Lopez-Sanchez, J. A., Conte, M., Landon, P., Zhou, W., Bartley, J. K., Taylor, S. H., and Hutchings, G. J. (2012). Reactivity of Ga2O3 Clusters on Zeolite ZSM-5 for the Conversion of Methanol to Aromatics. Catalysis letters, 142(9), 1049-1056. http://dx.doi.org/10.1007/s10562-012-0869-2

[7] Pecharsky, V. K., and Zavalij, P. Y. (2009). Fundamentals of powder diffraction and structural characterization of materials (Vol. 69). New York: Springer.

[8] Haber, J., Block, J. H., and Delmon, B. (1995). Manual of methods and procedures for catalyst characterization (Technical Report). Pure and applied chemistry, 67(8-9), 1257-1306. http://dx.doi.org/10.1351/pac199567081257

[9] Fricke, R., Kosslick, H., Lischke, G., and Richter, M. (2000). Incorporation of gallium into zeolites: Syntheses, properties and catalytic application. Chemical reviews, 100(6), 2303-2406. http://dx.doi.org/10.1021/cr9411637

[10] Hagen, A., and Roessner, F. (2000). Ethane to aromatic hydrocarbons: past, present, future. Catalysis Reviews, 42(4), 403-437. http://dx.doi.org/10.1081/CR-100101952

[11] Hutchings, G. J., Gottschalk, F., Hall, M. M., and Hunter, R. (1987). Hydrocarbon formation from methylating agents over the zeolite catalyst ZSM-5. Comments on the mechanism of carbon-carbon bond and methane formation. Journal of the Chemical Society, Faraday Transactions 1: Physical Chemistry in Condensed Phases, 83(3), 571-583.

[12] Csicsery, S. M. (1986). Catalysis by shape selective zeolites-science and technology. Pure and Applied Chemistry, 58(6), 841-856. http://dx.doi.org/10.1351/pac198658060841

[13] Freeman, D., Wells, R. P., and Hutchings, G. J. (2001). Methanol to hydrocarbons: enhanced aromatic formation using a composite Ga2O3-H-ZSM-5 catalyst. Chemical Communications, (18), 1754-1755. http://dx.doi.org/10.1039/b104844a

[14] Stöcker, M. (1999). Methanol-to-hydrocarbons: catalytic materials and their behavior. Microporous and Mesoporous Materials, 29(1), 3-48. http://dx.doi.org/10.1016/S1387-1811(98)00319-9

[15] Bjørgen, M., Joensen, F., Lillerud, K. P., Olsbye, U., and Svelle, S. (2009). The mechanisms of ethene and propene formation from methanol over high silica H-ZSM-5 and H-beta. Catalysis Today, 142(1), 90-97. http://dx.doi.org/10.1016/j.cattod.2009.01.015 